\title{
Depletion of neutrophils in a protective model of pulmonary cryptococcosis results in increased IL-17A production by gamma/delta T cells
}

\author{
Karen L Wozniak ${ }^{1,2}$, Jay K Kolls $s^{3}$ and Floyd L Wormley Jr $r^{1,2^{*}}$
}

\begin{abstract}
Protective responses in mice immunized with an interferon-gamma producing strain of Cryptococcus neoformans, $\mathrm{H} 99 \mathrm{\gamma}$, are associated with IL-17A production by neutrophils. Neutrophil depletion in H99Y-immunized mice did not affect pulmonary fungal burden, indicating that neutrophils are not required for clearance. However, we observed an increase in IL-17A in the lungs of neutrophil-depleted H99y infected mice, which corresponded to an increase in $\mathrm{IL}-17 \mathrm{~A}^{+} \gamma \delta^{+} T$ cells. Moreover, we observed increased IL-17A $/ \mathrm{CD}^{+}$cells and IL-17A $\mathrm{A}^{+} / \gamma \delta^{+}$cells, but decreased $\mathrm{IL}-17 \mathrm{~A}^{+} / \mathrm{Ly}_{6 \mathrm{G}}+$ neutrophils in the lungs of IL-17 receptor (R)A deficient mice compared to wild-type mice. Increased production of IL-17A in neutropenic mice coincided with increased IL-6 and CXCL1, but not Th17 inducing cytokines TGF- $\beta$, IL-21 and IL-23. Concurrent depletion of neutrophils and $\gamma \delta^{+} T$ cells reduced IL-17A levels. Our results suggest that $\gamma \delta^{+} T$ cells mediate significant IL-17A production in neutropenic mice during the protective response to $C$. neoformans infection.
\end{abstract}

Keywords: Gamma-delta T cells, Cryptococcus neoformans, IL-17A, Pulmonary

\section{Background}

Cryptococcus neoformans is an opportunistic fungal pathogen that primarily affects patients with impaired $\mathrm{T}$ cellmediated immunity. Clinically, symptomatic cryptococcal infections have been observed in individuals with AIDS, solid-organ transplant recipients receiving immunosuppressive medicines to prevent organ rejection, and patients taking chemotherapeutic drugs [1-5]. Experimental studies in mice have suggested that protection against cryptococcosis is primarily associated with the induction of Th1-type anti-cryptococcal cell-mediated immune responses [6-13]. In addition, Th17-type immune responses have been shown to be important for protection against multiple fungal pathogens [14-18]. However, the specific function of IL-17A and/or Th17-type immune responses in mediating protection against cryptococcal infection is uncertain [19-23].

\footnotetext{
*Correspondence: floyd.wormley@utsa.edu

'Department Biology, The University of Texas at San Antonio, San Antonio, TX 78249-0062, USA

${ }^{2}$ The South Texas Center for Emerging Infectious Diseases, The University of Texas at San Antonio, San Antonio, TX, USA

Full list of author information is available at the end of the article
}

Previously, we have shown that mice immunized with an interferon-gamma (IFN- $\gamma$ ) producing strain of Cryptococcus neoformans, denoted $\mathrm{H} 99 \gamma$, were completely protected against subsequent challenge with wild-type cryptococci [11,12]. Protection was associated with the induction of Th1-type and pro-inflammatory cytokine responses and IL-17A production early during infection in protected animals $[11,12]$. While protection against $C$. neoformans strain $\mathrm{H} 99$ Y required intact Th1-type cytokine responses, mice depleted of IL-17A and IL-17 receptor (R) A deficient (IL-17RA ${ }^{-1-}$ ) mice were able to survive acute infection with $C$. neoformans strain $\mathrm{H} 99 \mathrm{\gamma}$ and no evidence of $\mathrm{H} 99 \mathrm{\gamma}$ dissemination to the brain was observed [24]. Furthermore, IL-17RA ${ }^{-/-}$mice immunized with $C$. neoformans strain $\mathrm{H} 99 \mathrm{y}$ were able to resolve a subsequent pulmonary challenge with wild-type C. neoformans strain H99. Nonetheless, some surviving IL-17RA ${ }^{-/-}$mice exhibited evidence of dissemination of C. neoformans to the brain that was not observed in their immune competent counterparts, suggesting that prevention of dissemination is an important protective feature of IL-17A during cryptococcosis [24]. Our prior studies using intracellular cytokine staining followed by 
flow cytometric analysis suggested that the primary producers of IL-17A in our model system were neutrophils rather than Th17-type $\mathrm{CD}^{+} \mathrm{T}$ cells [24]. Furthermore, the IL-17A produced in our model of cryptococcal infection was not proceeded or accompanied by the production of cytokines that typically initiate Th17-type responses (i.e., TGF- $\beta$, IL-21, or IL-23) [12]. This is not unique, as other investigators have observed IL-17A production by neutrophils in other model systems [25-27]. Also, IL-17A production by multiple cell types including $\mathrm{CD}^{+} \mathrm{T}$ cells, $\gamma \delta^{+} \mathrm{T}$ cells, NK cells, and NKT cells have been demonstrated [25,28-37]. In the current studies, we further explored the role of neutrophils and IL-17A production in mice during infection with $C$. neoformans strain $\mathrm{H} 99 \gamma$. Interestingly, depletion of neutrophils in mice infected with C. neoformans strain $\mathrm{H} 99 \gamma$ resulted in a significant increase of IL-17A in lung homogenates, which necessitated a search for alternate sources of IL17A in neutropenic mice. The eventual depletion of neutrophils in combination with other cell types led to the identification of $\gamma \delta^{+}$T cells as a source of IL-17A production during pulmonary infection with $C$. neoformans strain $\mathrm{H} 99 \gamma$.

\section{Results}

Depletion of neutrophils in mice infected with $C$. neoformans strain H99 $\mathrm{Y}$ leads to increased IL-17A in lung homogenates

Our previous work employing intracellular cytokine staining followed by flow cytometric analysis suggested that neutrophils were the primary leukocyte source of IL-17A in mice infected with C. neoformans strain H99y [24]. Therefore, we sought to determine the effect of neutrophil depletion on IL-17A production in the lungs of mice during infection with $C$. neoformans strain $\mathrm{H} 99 \gamma$. Mice were depleted of neutrophils using two different neutrophil depletion antibodies, the anti-Gr1 antibody (clone RB6-8C5) and the anti-Ly6G antibody (clone 1A8), and control animals were treated with isotype control antibody beginning 24 hours prior to infection and every 48 hours thereafter. Total leukocytes were isolated from lung digests on day 7 post-infection to confirm neutrophil depletion and to phenotype the local leukocyte population. This time point was chosen because it is the time point at which pulmonary IL-17A production is at its peak during infection with C. neoformans strain $\mathrm{H} 99 \gamma$ [24]. Additionally, protein homogenates were prepared from lung tissues on day 7 post-infection to evaluate pulmonary IL-17A cytokine production and fungal burden in neutrophil depleted mice compared to isotype control antibody treated animals. Each depletion protocol implemented resulted in a successful depletion of both the absolute cell numbers and percentage of neutrophils present in the lungs compared to isotype control antibody treated mice (Figure 1A and B). Following neutrophil depletion with either antibody, fungal burden was not significantly different compared to that observed in isotype control antibody treated animals at day 7 post-inoculation (Figure $1 \mathrm{C}$ and $\mathrm{D}$ ), as observed by previous investigators [38]. Interestingly, pulmonary homogenates of mice depleted of neutrophils by either antibody had significantly higher IL-17A present compared to mice treated with isotype control antibody (Figure $1 \mathrm{E}$ and F). While this result seemed counterintuitive, it is not unique and has been observed in other model systems during neutrophil depletion [26,39]. Previous studies have suggested that IL-10 production by neutrophils may lead to an inhibition of IL-17A production in the lungs [40]. However, we observed no significant difference in IL-10 present within lung homogenates derived from isotype control antibody treated mice in comparison to that observed in neutrophil depleted mice on day 7 postinoculation $(11.64 \mathrm{pg} / \mathrm{ml} \pm 1.36$ and $12.58 \mathrm{pg} / \mathrm{ml} \pm 0.94$, in isotype control antibody treated and clone $1 \mathrm{~A} 8$ treated mice, respectively). Due to its cross-reactivity to the Ly6C antigen, the anti-Gr1 antibody depleted not only neutrophils but also $\mathrm{CD}^{+} \mathrm{T}$ cells (data not shown), as seen in studies by other investigators [41]. In contrast, the $1 \mathrm{~A} 8$ clone was observed to specifically deplete neutrophils. Other leukocyte populations examined following $1 \mathrm{~A} 8$ neutrophil depletion $\left(\mathrm{CD}^{+} \mathrm{T}\right.$ cells, $\mathrm{CD}^{+} \mathrm{T}$ cells, macrophages, dendritic cells, regulatory $\mathrm{T}$ cells, natural killer T cells, $\gamma \delta^{+}$T cells, natural killer cells, eosinophils, and B cells) were not affected (data not shown). Therefore, we elected to perform all further experiments using the $1 \mathrm{~A} 8$ antibody for neutrophil depletion.

\section{Determination of IL-17A-producing population in the absence of neutrophils}

We sought to determine the population responsible for the increased production of IL-17A in the lungs of neutrophil depleted mice on day 7 post-infection with $C$. neoformans strain $\mathrm{H} 99 \gamma$. Total leukocytes were isolated from lung tissues, and the leukocyte subpopulations were characterized for intracellular IL-17A expression by flow cytometry. Leukocyte populations examined included neutrophils, $\mathrm{CD}^{+}{ }^{+} \mathrm{T}$ cells, $\mathrm{CD}^{+} \mathrm{T}$ cells, macrophages, dendritic cells, regulatory $\mathrm{T}$ cells, natural killer $\mathrm{T}$ cells, natural killer cells, $\gamma \delta^{+} \mathrm{T}$ cells, B cells, and eosinophils. Figure 2 demonstrates that the only cell type with increased intracellular IL-17A expression during neutrophil depletion was the $\gamma \delta^{+} \mathrm{T}$ cell population. As expected, the percentage of IL- $17 \mathrm{~A}^{+}$neutrophils was significantly reduced in neutrophil depleted mice, and other leukocyte subsets including $\mathrm{CD}^{+}{ }^{+} \mathrm{T}$ cells and dendritic cells had significantly reduced intracellular staining for IL-17A following neutrophil depletion (Figure 2). 

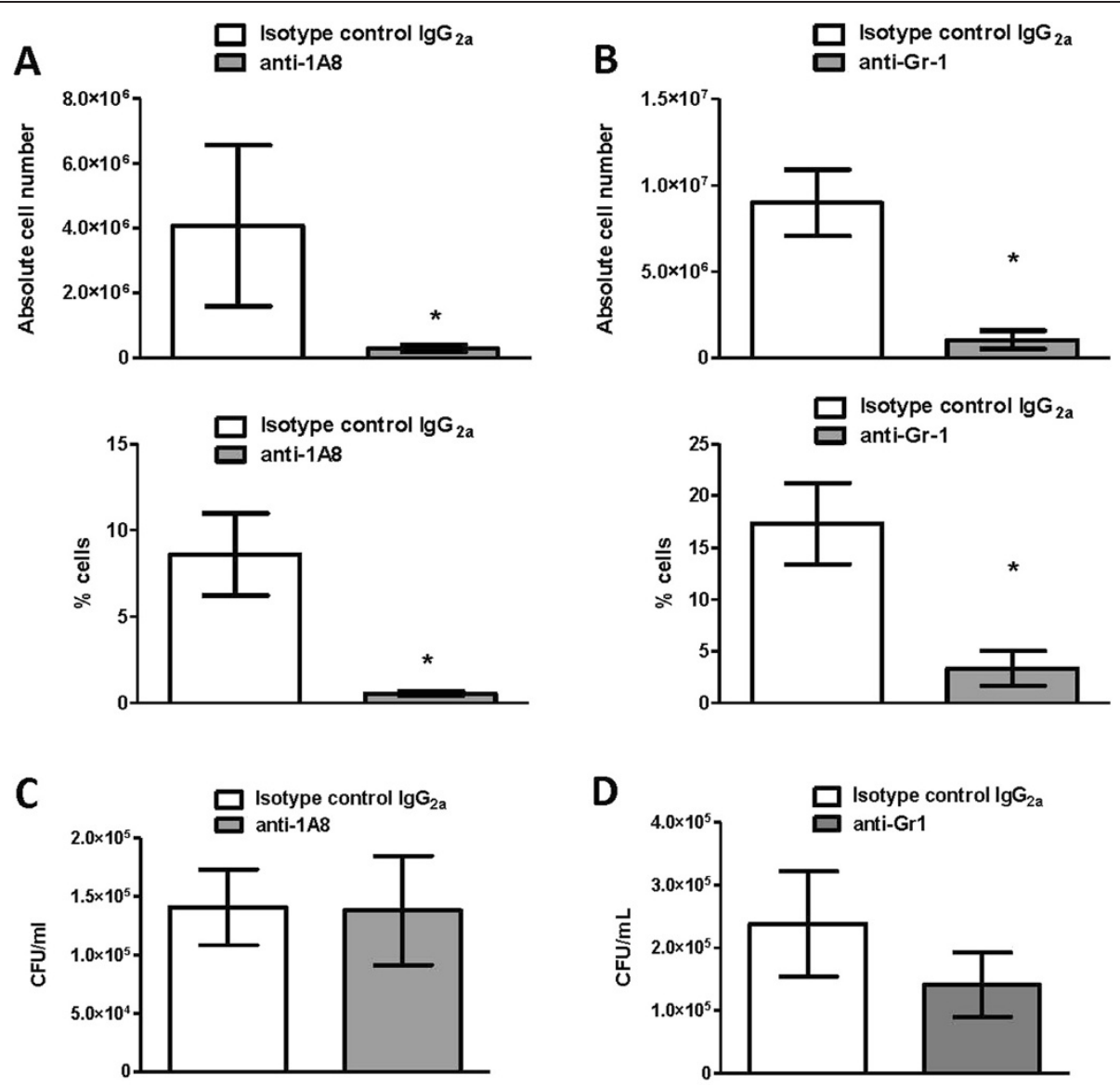

$\mathbf{E}$

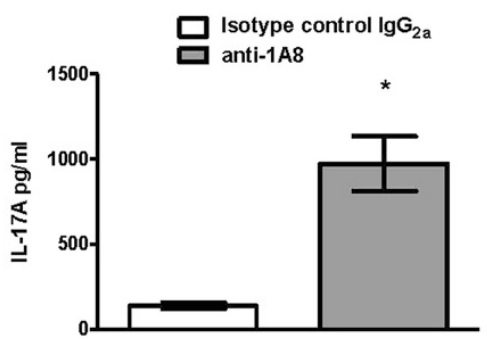

$\mathbf{F}$

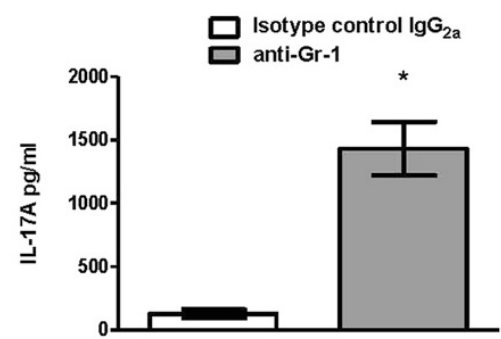

Figure 1 Neutrophil depletion does not influence fungal burden but is associated with increased pulmonary levels of IL-17A during infection with $\mathrm{C}$. neoformans strain H99\%. BALB/C mice received an intranasal inoculum of $1 \times 10^{4} \mathrm{CFU}$ of $\mathrm{C}$. neoformans strain $\mathrm{H} 99 \mathrm{y}$ in $50 \mu \mathrm{l}$ of sterile PBS. Prior to and during infection, mice were treated with isotype control antibody (white bars) or with either anti-1A8 antibody or anti-Gr1 antibody (gray bars). Lungs were excised at day 7 post-inoculation, and neutrophil depletion, absolute numbers and percentages $(\mathbf{A}, \mathbf{B})$, pulmonary cryptococcal burden $(\mathbf{C}, \mathbf{D})$ and IL-17A production $(\mathbf{E}, \mathbf{F})$ quantified. Asterisks $\left(^{*}\right)$ indicate where significant differences $(P<0.05)$ were observed in neutrophil depleted mice compared to isotype-control treated mice following infection with C. neoformans strain H99ץ. Fungal burden results are expressed as mean CFU per milliliter \pm standard errors of the means. Data are cumulative of four experiments using 4 mice per group.

\section{Ex vivo IL-17 production in $\gamma \delta^{+} \mathrm{T}$ cells from neutrophil} depleted mice

In order to confirm our observation that $\gamma \delta^{+} \mathrm{T}$ cells had increased IL-17A production in mice depleted of neutrophils, we isolated $\gamma \delta^{+} \mathrm{T}$ cells from $\mathrm{H} 99 \gamma$-infected mice treated with either isotype control antibody or the 1A8 neutrophil-depleting antibody on day 7 post-infection.
Once isolated, $\gamma \delta^{+} \mathrm{T}$ cells were plated in tissue culture wells with and without cryptococcal antigen for $24 \mathrm{~h}$. Following incubation, supernatants were harvested and examined for IL-17A by ELISA, and cells were examined for intracellular IL-17A by flow cytometry. Results showed that IL-17A protein levels (Figure 3A) as well as intracellular IL-17A (Figure 3B) were significantly 


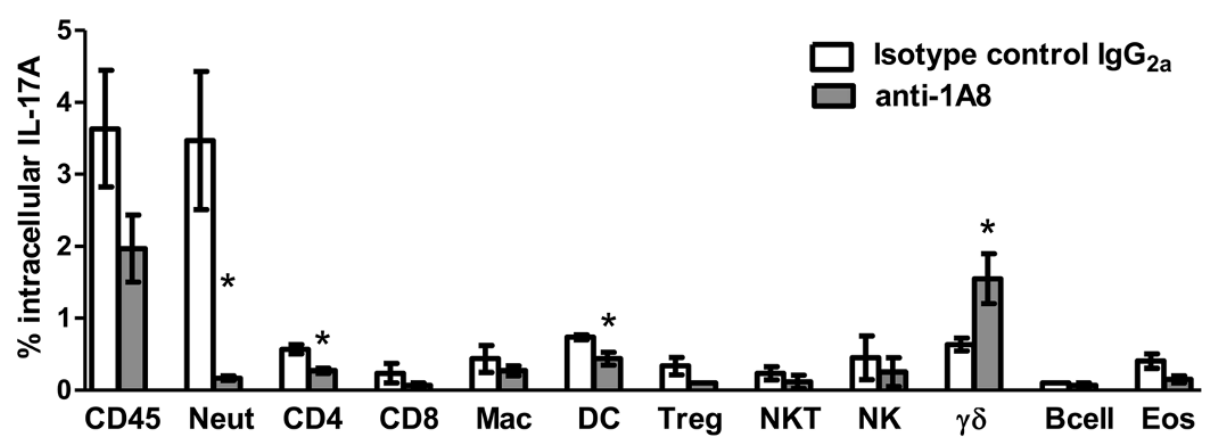

Figure 2 Lung $\gamma \delta^{+}$T cells are the predominant leukocyte population expressing IL-17A during pulmonary infection with C. neoformans strain $\mathrm{H} 99 \mathrm{\gamma}$ during neutrophil depletion. BALB/C mice received an intranasal inoculum of $1 \times 10^{4} \mathrm{CFU}$ of $\mathrm{C}$. neoformans strain $\mathrm{H} 99 \mathrm{y}$ in $50 \mu \mathrm{l}$ of sterile PBS. Mice were treated with isotype control antibody (white bars) or with anti-1A8 antibody (gray bars). The lungs were excised at day 7 post-inoculation and a single cell suspension generated using enzymatic digestion. The leukocytes were stained with anti-mouse antibodies

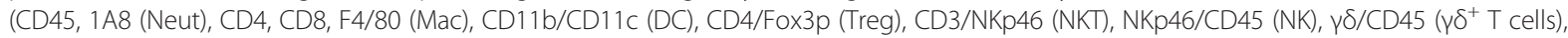
CD19 (B cell), SiglecF/CD11b (Eosinophil), fixed, permeabilized, and incubated with anti-IL-17A antibodies and evaluated by flow cytometry. Flow cytometry data are cumulative results of three independent experiments using pooled leukocytes from 4 mice per group per experiment. Results shown are the percentage of leukocytes expressing the indicated surface markers and IL-17A. Asterisks $\left(^{*}\right)$ indicate where significant differences $(P<0.05)$ were observed between isotype control-treated and anti-1A8-treated mice infected with $C$. neoformans strain H99ץ.

increased in $\gamma \delta^{+} \mathrm{T}$ cells from neutrophil-depleted mice compared to isotype control-treated mice, therefore confirming our previous observations (Figure 2).

\section{Cytokine production and intracellular IL-17A expression in mice deficient in IL-17RA signaling}

We hypothesized that intracellular staining for IL-17A may be indicative of which cells produce IL-17A; therefore, we wanted to rule out the possibility that our intracellular staining may be detecting the recipients of IL-17A. Consequently, we evaluated IL-17A production in IL-17RA ${ }^{-1-}$ mice compared to wild-type mice on day 7 following infection with C. neoformans strain H99y. We rationalized that increased cellular production of IL-
17A will be observed but IL-17A uptake will not be detected in IL-17RA ${ }^{-1-}$ mice, thus providing some insight into which cells are the producers and/or the target for IL-17A in our model system. We observed a significant increase in IL-17A within lung homogenates derived from IL-17RA ${ }^{-1-}$ mice compared to wild-type mice on day 7 post-infection with $C$. neoformans strain H99y (Figure 4A). Total leukocytes were also isolated from lung tissues, and the leukocyte subpopulations characterized for intracellular IL-17A expression by flow cytometry. We observed an overall decrease, though not reaching statistical significance, in the percentage of IL$17 \mathrm{~A}^{+}$neutrophils in IL-17RA ${ }^{-1-}$ mice compared to wildtype mice. However, significantly increased IL-17A ${ }^{+} / \mathrm{CD}^{+}$
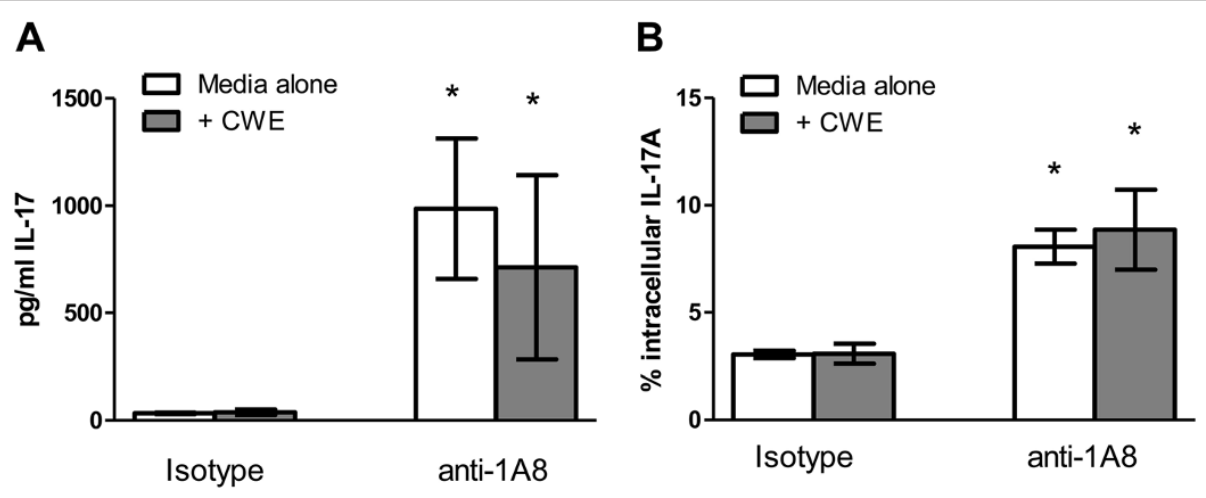

Figure 3 Ex-vivo IL-17A production from $\gamma \delta^{+} \mathbf{T}$ cells following neutrophil depletion. BALB/c mice received an intranasal inoculum of $1 \times 10^{4}$ CFU of C. neoformans strain $\mathrm{H} 99 \mathrm{y}$ in $50 \mu \mathrm{l}$ of sterile PBS. Mice were treated with isotype control antibody or with anti-1A8 antibody. The lungs were excised at day 7 post-inoculation and a single cell suspension generated using enzymatic digestion. The leukocytes were isolated and then further purified for $\gamma \delta^{+} \mathrm{T}$ cells. The $\gamma \delta^{+} \mathrm{T}$ cells were plated at $1 \times 10^{5}$ cells/well and incubated for $24 \mathrm{~h}$ at $37^{\circ} \mathrm{C}, 5 \% \mathrm{CO}_{2}$ with media alone (white bars) or with C. neoformans cell wall extract (CWE) (gray bars). Cell supernatants were removed and examined for IL-17A by ELISA. Asterisks (*) indicate where significant differences $(P<0.05)$ were observed between $\gamma \delta^{+} T$ cells from mice treated with isotype control antibody compared to those from mice treated with the 1A8 neutrophil depletion antibody. Data are cumulative of three separate experiments. 

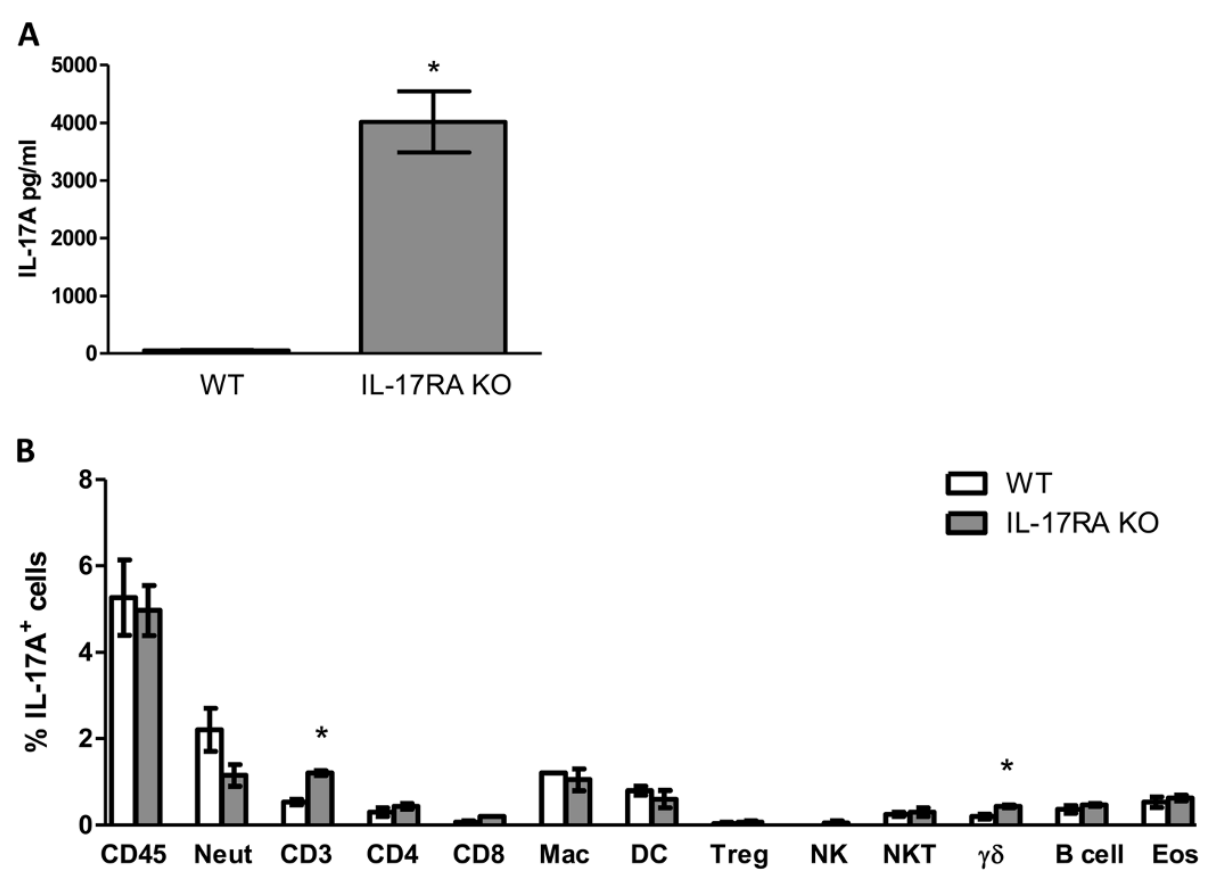

Figure 4 Induction of IL-17A production during $C$. neoformans strain H99 $\gamma$ infection requires signaling through the IL-17A receptor. $\mathrm{BALB} / \mathrm{C}$ (white bars) and IL-17RA KO (gray bars) mice were given an intranasal inoculation with C. neoformans strain H99y. Lungs were excised at day 7 post-inoculation, and pulmonary cytokine production quantified (A) and intracellular IL-17A production was determined in leukocyte populations (B). The lungs were excised at day 7 post-inoculation and a single cell suspension generated using enzymatic digestion. The leukocytes were stained with anti-mouse antibodies (CD45, 1A8 (Neut), CD4, CD8, F4/80 (Mac), CD11b/CD11c (DC), CD4/Fox3p (Treg), CD3/NKp46 (NKT), NKp46/CD45 (NK), үס/CD45 ( $\gamma \delta^{+}$T cells), CD19 (B cell), SiglecF/CD11b (Eosinophil), fixed, permeabilized, and incubated with anti-mouse antibodies specific for IL-17A and quantified by flow cytometry. Asterisks $\left(^{*}\right)$ indicate where significant differences $(P<0.05)$ were observed between WT and IL-17RA KO mice infected with C. neoformans strain H99y. Data are cumulative of three experiments using 3 mice per group.

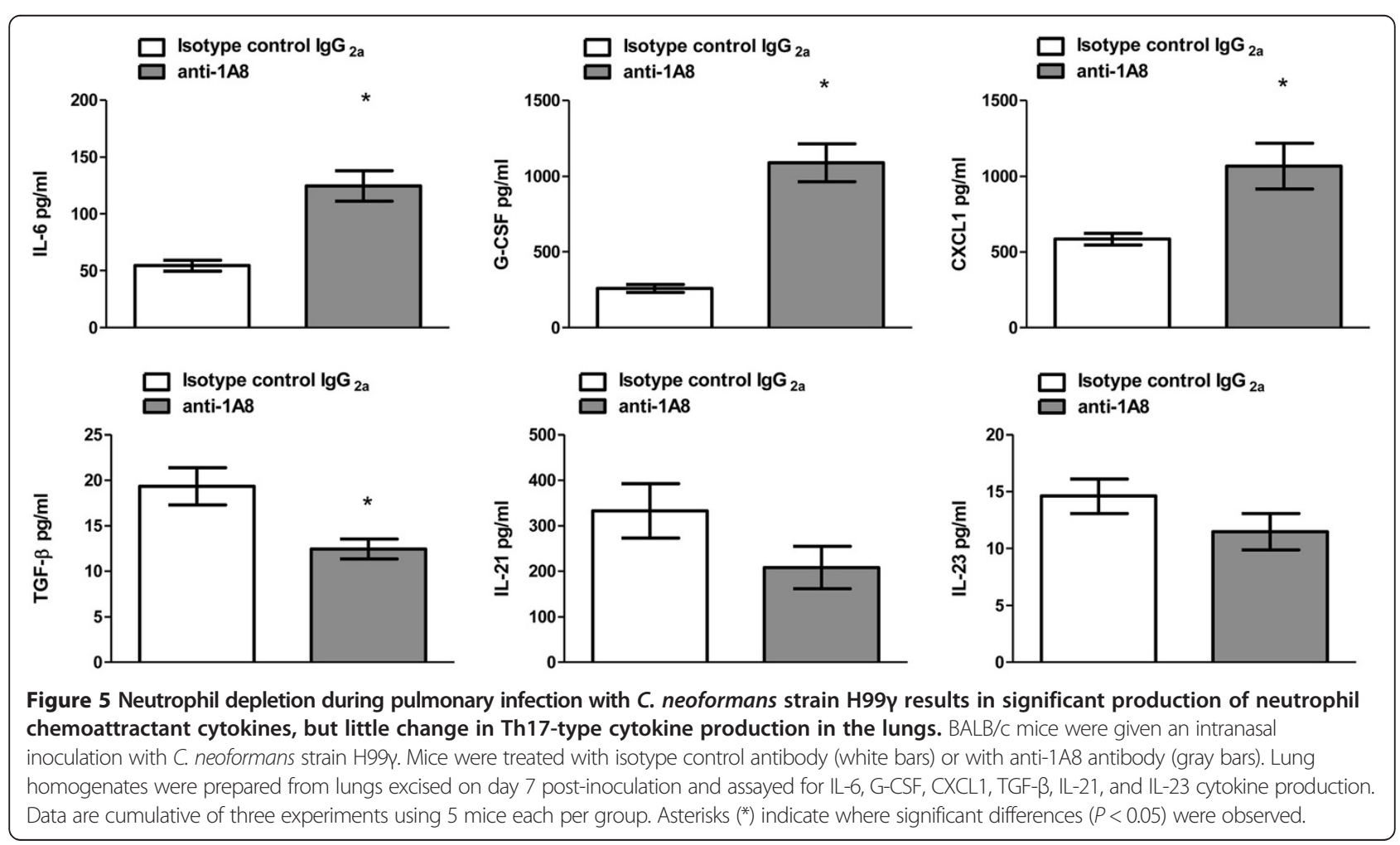


and IL-17 $\mathrm{A}^{+} / \gamma \delta^{+} \mathrm{T}$ cell populations were also observed in the lungs of IL-17RA ${ }^{-1-}$ mice compared to wild-type mice on day 7 post-infection (Figure 4B). No other significant differences were observed.

\section{Cytokine and chemokine production in mice depleted of neutrophils}

We posited that other cytokines/chemokines known to induce neutrophil chemotaxis may be increased in the lungs of neutrophil depleted mice following infection with $\mathrm{H} 99 \gamma$, since recruitment of neutrophils occurs during infection with $\mathrm{H} 99 \gamma$. Therefore, we determined the expression of cytokines involved in neutrophil recruitment, including IL-6, G-CSF, and CXCL1, within the lungs of neutrophil depleted and isotype control antibody treated mice on day 7 post-infection with C. neoformans strain $\mathrm{H} 99 \gamma$. As shown in Figure 5A, IL6, G-CSF, and CXCL1 were significantly increased in the lung homogenates of neutrophil depleted mice compared to lung homogenates of isotype control antibody treated mice, suggesting an attempt by the host to recruit neutrophils to the site of infection. Cytokines typically associated with a Th17-type response, IL-21, IL-23, and TGF- $\beta$, were also investigated to support our previous observation that the IL-17A response to this infection is part of an overall chemokine response and not associated with a classical Th17-type response. IL-21 and IL-23 levels were not significantly changed during neutrophil depletion, and TGF- $\beta$ was significantly decreased in neutrophil depleted mice in comparison to isotype control antibody treated mice (Figure 5B).

\section{Depletion of additional leukocyte populations during neutrophil depletion}

Our observation that $\mathrm{CD}^{+}$and $\gamma \delta^{+}$cells have significantly increased intracellular IL-17A production during neutrophil depletion led us to examine these populations more closely. For this, mice were depleted of neutrophils alone, or neutrophils in combination with $\mathrm{CD} 4^{+} \mathrm{T}$ cells and/or $\mathrm{CD}^{+} \mathrm{T}$ cells, and $\gamma \delta^{+} \mathrm{T}$ cells and given an experimental pulmonary infection with $C$. neoformans strain $\mathrm{H} 99 \gamma$. IL-17A production and pulmonary fungal burden was subsequently analyzed on day 7 postinoculation. Depletion of neutrophils in combination with $\mathrm{CD}^{+}$and/or $\mathrm{CD}^{+}$T cell subsets did not affect IL$17 \mathrm{~A}$ production in the lungs of infected mice compared to infected mice treated with isotype control antibody (Figure 6A). In contrast, depletion of neutrophils in combination with $\gamma \delta^{+} \mathrm{T}$ cells resulted in a significant reduction in pulmonary IL-17A compared to IL-17A detected in lung homogenates of mice depleted of neutrophils alone on day 7 post-infection (Figure 5A). Nonetheless, we observed no significant difference in pulmonary fungal burden in all depletion groups at day

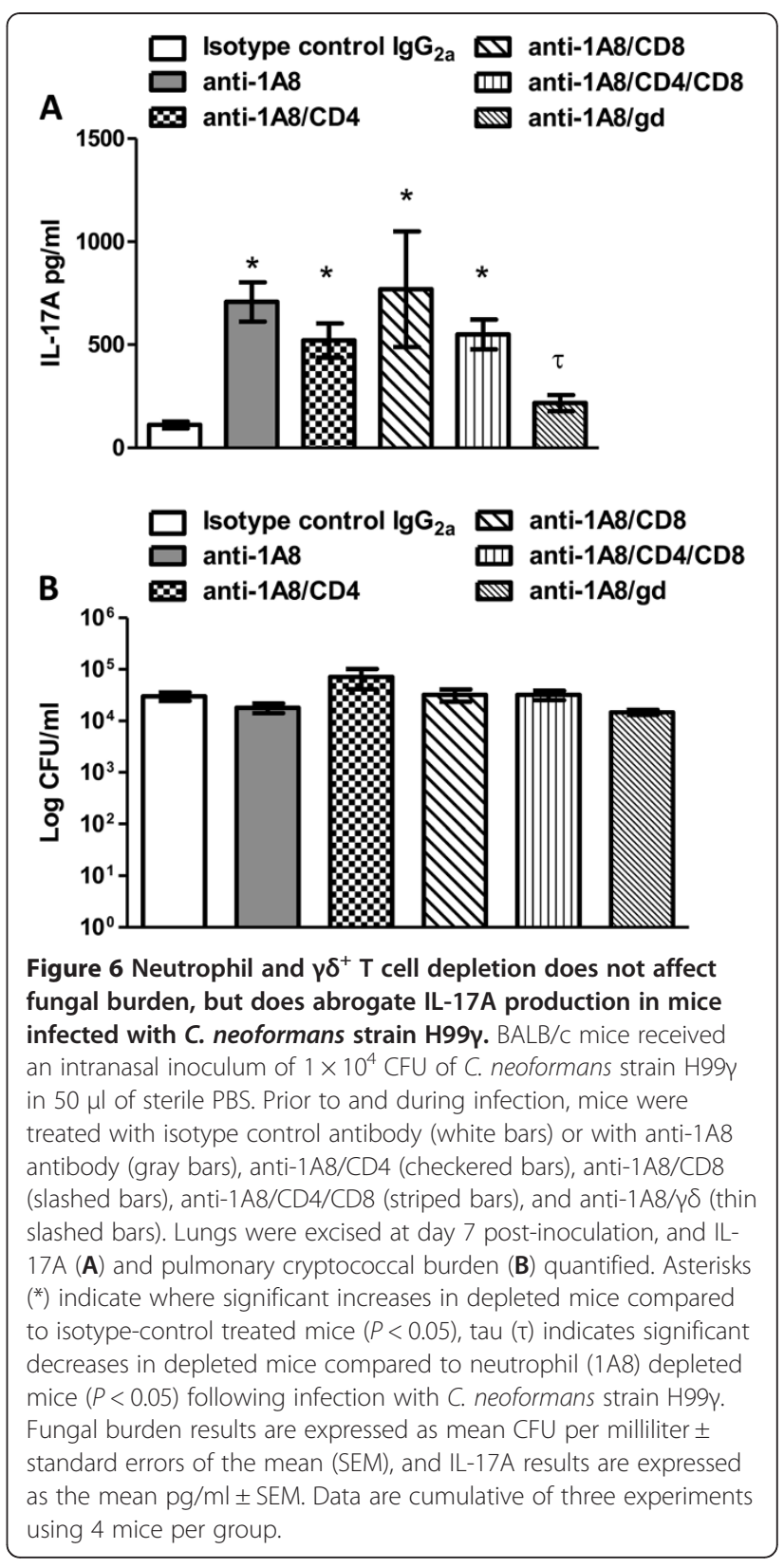

7 post-infection (Figure 6B). Therefore, the $\gamma \delta^{+} \mathrm{T}$ cells appear to be responsible for the increased IL-17A detected in lung homogenates of neutropenic mice infected with C. neoformans strain $\mathrm{H} 99 \gamma$.

\section{Discussion}

Our results discussed herein show that $\gamma \delta^{+} \mathrm{T}$ cells produce significant quantities of IL-17A in mice depleted of neutrophils during pulmonary infection with $C$. neoformans strain $\mathrm{H} 99 \gamma$. The production of IL-17A did not appear commensurate with the percentage of IL-17A ${ }^{+} \gamma \delta^{+}$ $\mathrm{T}$ cells observed in pulmonary tissues of $C$. neoformans 
strain $\mathrm{H} 99 \gamma$ infected mice. Nonetheless, dual depletion of neutrophils and $\gamma \delta^{+} \mathrm{T}$ cells resulted in a significant reduction in pulmonary IL-17A production compared to mice depleted of neutrophils alone. This may suggest that neutrophils negatively regulate the production of IL-17A from $\gamma \delta^{+}$T cells. Previous studies have suggested that IL-10 production by neutrophils may lead to an inhibition of IL-17A production in the lungs [40], however, we observed no evidence of this occurring in our model system. Alternatively, the presence of cytokines or other stimulants that promote IL-17A production by $\gamma \delta^{+} \mathrm{T}$ cells may be enhanced in the lungs of neutrophil depleted mice in our model system. Thus, neutrophils would only indirectly influence IL-17A production by $\gamma \delta^{+} \mathrm{T}$ cells. While we are uncertain of the mechanism, we are not the first to demonstrate a contribution by $\gamma \delta^{+} \mathrm{T}$ cells to IL-17A production [27,29-31,34,35], and these data provide us with additional insight into perhaps an underappreciated role of $\gamma \delta^{+}$T cells in cytokine production at the pulmonary mucosa. In our model of protection against pulmonary cryptococcosis using $C$. neoformans strain $\mathrm{H} 99 \gamma$, IL-17A production appears to work in concert with Th1-type immune responses to mediate protection and prevent dissemination to the brain $[11,12]$. Previous experiments employing intracellular staining for IL-17A followed by flow cytometric analysis indicated neutrophils as the predominant source of IL-17A in the lung during protective anticryptococcal immune responses [24]. Neutrophils do not appear to be critical for clearance of pulmonary C. neoformans infections; indeed, depletion of neutrophils alone in mice was shown to prolong survival and lower fungal burden [38]. However, neutrophils are phagocytic, anti-fungal, and also participate in the production of cytokines that enhance protective anti-cryptococcal immune responses [41-44]. Quite possibly, other cell types assume a greater effector role against $C$. neoformans to compensate for the absence of neutrophils in the lung.

The $\gamma \delta^{+}$T cell is an often overlooked cell type in immunity, but recent reports indicate that these cells provide critical protection in response to a variety of infections $[39,45]$. Their role in protection and IL-17A production has also recently been shown in several different models $[28,35,36]$, thus supporting these current findings. While these cells were originally thought to be a primordial innate $\mathrm{T}$ cell with no memory capabilities (reviewed in [46]), more recent studies have shown that $\gamma \delta^{+} \mathrm{T}$ cells actually can respond to pathogen challenge and may function as a bridge between innate and adaptive immune responses [45]. Recent studies with the fungal organism Candida albicans have shown that IL-17A production by $\gamma \delta^{+} \mathrm{T}$ cells is important in early protection [39]. However, a previous study examining $\gamma \delta \mathrm{KO}$ mice as well as depletion of $\gamma \delta^{+} \mathrm{T}$ cells during cryptococcal infection showed enhanced fungal clearance [39]. In our model, which uses a different strain of mice and Cryptococcus, however, depletion of $\gamma \delta^{+}$T cells did not affect pulmonary fungal burden at early time points. Future studies in our laboratory will address the role of $\gamma \delta^{+} \mathrm{T}$ cells in mediating long-term protection during acute infection with our protective $\mathrm{H} 99 \gamma$ strain and subsequent survival following challenge with wildtype C. neoformans strain H99.

We previously showed that immunization with $C$. neoformans strain $\mathrm{H} 99 \gamma$ induced protection against a subsequent intranasal challenge with wild-type $C$. neoformans strain $\mathrm{H} 99$ in mice depleted of $\mathrm{CD}_{4}^{+} \mathrm{T}$ cells and/or $\mathrm{CD}^{+}$ T cells [47]. Clinically, we know that $C$. neoformans infection results in significant morbidity and mortality in immune compromised individuals with low $\mathrm{CD}^{+} \mathrm{T}$ cells [1-5]. Traditional "innate" cell populations, such as NK cells, NKT cells, LTi cells, and $\gamma \delta^{+}$T cells can mediate protective immunity in the presence or absence of traditional adaptive mechanisms [48-52]. Demonstrating that cell populations such as $\gamma \delta^{+} \mathrm{T}$ cells participate in protective anti-cryptococcal immune responses and uncovering a means to enhance these responses will be critical to the development of effective immune therapies and/or vaccines targeted for use in immunocompromised patient populations.

In these data presented herein, we used intracellular cytokine staining followed by flow cytometry analysis to determine the IL-17A-producing population of cells within mice given an experimental pulmonary infection with $C$. neoformans strain H99y. However, we acknowledge that this technique may not adequately represent the entire picture since intracellular staining only allows us to identify the percentage of positively-stained cells, and therefore it is not quantitative. Therefore, it is possible that we may be underestimating the contributions of specific leukocyte populations as producers of IL17A, since we cannot determine the specific amount of IL-17A produced by each individual cell type using intracellular staining alone. Also, intracellular staining may identify cells that are the target cells for the cytokine, in addition to cells producing the cytokine. Further, our ex vivo data using purified $\gamma \delta^{+}$T cells from H99 $\gamma$-infected mice depleted of neutrophils verified their IL-17A production. Our results using mice deficient in IL-17RA signaling show that the percentage of IL-17A ${ }^{+}$ neutrophils were decreased by approximately $47 \%$ compared to wild-type mice during infection with $C$. neoformans strain $\mathrm{H} 99 \gamma$, which supports this conclusion. In addition to $\gamma \delta^{+} \mathrm{T}$ cells, other $\mathrm{CD}^{+}$cells can also produce IL-17A, including invariant natural killer cells (iNK) and lymphoid tissue inducer cells (LTi) [53-55]. However, we examined these cell types and did not observe the presence of these cells in the lung during 
infection with C. neoformans strain H99y (Wozniak \& Wormley, unpublished observations).

\section{Conclusions}

In conclusion, the data presented herein describe the identification of the $\gamma \delta^{+} \mathrm{T}$ cell as a significant source of IL-17A in the lungs of neutropenic mice during infection with C. neoformans strain H99y. Depletion of these cells leads to abrogation of the enhanced IL-17A production observed upon depletion of neutrophils during infection with the protective C. neoformans strain H99y. These $\gamma \delta^{+} \mathrm{T}$ cells may play an important role in leukocyte chemotaxis and the induction of protective immune responses to $C$. neoformans, especially in the absence of traditional adaptive immune responses. If this proves to be the case, these findings may have implications in the design of treatments or vaccines to combat cryptococcal disease. Ongoing studies are examining the role of these cells during challenge with wild-type $C$. neoformans strain $\mathrm{H} 99$, and their potential role in animals lacking all traditional adaptive immune cell types.

\section{Methods}

Mice

Female BALB/c $\left(\mathrm{H}-2^{\mathrm{d}}\right)$ (National Cancer Institute/ Charles River Laboratories, Boston, MA and The Jackson Laboratory, Bar Harbor, ME) and IL-17 receptor A knock out (IL-17RA ${ }^{-1-}$ ) mice (a kind gift of Amgen, Inc. Thousand Oaks, CA), all on the BALB/c background with an average weight of 20-25 grams, were used throughout these studies. This study was carried out in strict accordance with the recommendations in the Guide for the Care and Use of Laboratory Animals of the National Institutes of Health. Mice were housed at The University of Texas at San Antonio Small Animal Laboratory Vivarium. These animal experiments were approved by The University of Texas at San Antonio Institutional Animal Care and Use Committee (IACUC), and mice were handled according to IACUC guidelines. All efforts were made to minimize animal suffering.

\section{Strains and media}

C. neoformans strain $\mathrm{H} 99 \gamma$ (serotype A, Mat $\alpha$, an interferon-gamma producing strain derived from C. neoformans H99 [11]) was recovered from 15\% glycerol stocks stored at $-80^{\circ} \mathrm{C}$ prior to use in the experiments described herein. The strain was maintained on yeast-extract-peptone-dextrose (YPD) media ( $1 \%$ yeast extract, $2 \%$ peptone, $2 \%$ dextrose, and $2 \%$ Bacto agar) supplemented with nourseothricin. Yeast cells were grown for $18-20 \mathrm{~h}$ at $30^{\circ} \mathrm{C}$ with shaking in YPD broth (Becton Dickinson and Company, Sparks, MD), collected by centrifugation, washed three times with sterile phosphatebuffered saline (PBS), and viable yeast quantified using trypan blue dye exclusion in a hemacytometer. For tissue culture, complete medium consisted of RPMI 1640 supplemented with $10 \%$ heat-inactivated fetal bovine serum, $2 \mathrm{mM} \mathrm{L}$-glutamine, $100 \mathrm{U}$ penicillin $/ \mathrm{ml}, 100 \mu \mathrm{g}$ of streptomycin $/ \mathrm{ml}$, and $50 \mathrm{mM}$ 2-mercaptoethanol.

\section{Pulmonary infections}

Pulmonary C. neoformans infections were initiated by nasal inhalation as previously described [12]. BALB/c mice were anesthetized with $2 \%$ isoflurane using a rodent anesthesia device (Eagle Eye Anesthesia, Jacksonville, FL) and then given a yeast inoculum of $1 \times 10^{4}$ colony forming units (CFU) of $C$. neoformans strain $\mathrm{H} 99 \gamma$ in $50 \mu \mathrm{l}$ of sterile PBS pipetted directly into the nares. The inocula used were verified by quantitative culture on YPD agar. The mice were fed ad libitum and were monitored by inspection twice daily. Mice were euthanized at specific time points post-inoculation by $\mathrm{CO}_{2}$ inhalation followed by cervical dislocation, and lung tissues were excised using aseptic technique. Tissues were homogenized in $1 \mathrm{ml}$ of sterile PBS, followed by culture of 10-fold dilutions of each tissue on YPD agar supplemented with chloramphenicol (Mediatech, Inc., Herndon, VA). CFU were enumerated following incubation at $30^{\circ} \mathrm{C}$ for $48 \mathrm{~h}$.

\section{Pulmonary leukocyte isolation}

Lungs were excised at specific time points postinoculation and digested enzymatically at $37^{\circ} \mathrm{C}$ for 30 minutes in $10 \mathrm{ml}$ of digestion buffer (RPMI 1640 and $1 \mathrm{mg} / \mathrm{ml}$ of collagenase type IV [Sigma-Aldrich, St. Louis, MO.]) with intermittent (every $10 \mathrm{~min}$ ) stomacher homogenizations. The enzymatically-digested tissues were then successively filtered through sterile nylon filters of various pore sizes (70 and $40 \mu \mathrm{m}$ ) (BD Biosciences) and washed with sterile HBSS to enrich for leukocytes. Erythrocytes were lysed by incubation in $\mathrm{NH} 4 \mathrm{Cl}$ buffer $\left(0.859 \% \mathrm{NH}_{4} \mathrm{Cl}, 0.1 \% \mathrm{KHCO}_{3}, 0.0372 \%\right.$ $\mathrm{Na}_{2}$ EDTA [pH 7.4]; Sigma-Aldrich) for 3 minutes on ice followed by the addition of a 10-fold excess of PBS. The resulting leukocyte population was then collected by centrifugation $(800 \times g)$ for 5 minutes, washed twice with sterile PBS, resuspended in sterile PBS $+2 \%$ heat-inactivated fetal bovine serum (FACS buffer) and enumerated in a hemacytometer using trypan blue dye exclusion. Flow cytometric analysis was used to determine the percentage of each leukocyte population as well as the absolute number of total leukocytes $\left(\mathrm{CD} 45^{+}\right)$ within the lung cell suspension for standardization of hemacytometer counts.

\section{Cell depletions}

For neutrophil depletion experiments, mice received either $200 \mu \mathrm{g}$ anti-Gr1 antibody (clone RB6-8C5) (BioXCell) 
or $200 \mu \mathrm{g}$ anti-Ly6G antibody (clone 1A8) (BioXCell) in a volume of $100 \mu \mathrm{l}$ injected intraperitoneally beginning 24 hours post-inoculation and continuing every other day throughout the study. For depletion of gamma-delta $\mathrm{T}$ cells, mice received $100 \mu \mathrm{g}$ anti-gamma-delta $\mathrm{T}$ cell receptor antibody (eBioscience) via the intraperitoneal route beginning two days prior to inoculation and continued weekly throughout the experiment. These concentrations and schedules were chosen following studies testing different dosages and schedules in our laboratory to determine the optimum dosage and schedule for each antibody (data not shown). Controls for neutrophil and $\gamma \delta^{+} \mathrm{T}$ cell depletions included mice treated with $\operatorname{IgG}_{2 \mathrm{a}}$ isotype control antibody (eBioscience Inc., San Diego, $\mathrm{CA})$ via the intraperitoneal route. Mice were depleted of $\mathrm{CD}^{+}$and/or $\mathrm{CD}^{+} \mathrm{T}$ cell subsets via intraperitoneal administration of anti-CD4 (GK1.5, rat $\operatorname{IgG}_{2 \mathrm{~b}}$ ) and antiCD8 $\alpha$ (2.43, rat $\operatorname{IgG}_{2 b}$ ) antibodies (each from National Cell Culture Center, Minneapolis, MN). Each mouse received $200 \mu \mathrm{g}$ of GK1.5 and/or 2.43 or control rat $\operatorname{IgG}_{2 \mathrm{~b}}$ (eBioscience Inc.) antibodies in a volume of $100 \mu \mathrm{l}$ PBS $48 \mathrm{~h}$ prior to infection and weekly thereafter. Cellular depletions were confirmed for each experiment by flow cytometry using antibodies that adhere to epitopes distinct from those adhered to by the depletion antibodies. Antibodies depleted approximately 95\% of neutrophils, $98 \%$ of $\gamma \delta^{+} \mathrm{T}$ cells, $98 \%$ of $\mathrm{CD}^{+} \mathrm{T}$ cells, and 98\% of $\mathrm{CD}^{+} \mathrm{T}$ cells (data not shown).

\section{Antibodies}

For flow cytometry experiments, cells were incubated with CD16/CD32 (Fc Block ${ }^{\text {TM }}$ ) (BD Biosciences, San Diego, CA) and the following antibodies conjugated to phycoerythrin (PE), allophycocyanin (APC), Alexa 647, or PECy7 were added: a cocktail of CD3, CD4, and CD8 $\alpha$; CD45, CD19, Siglec-F (BD Biosciences), 1A8, CD11c, CD11b, F4/80, NKp46, Fox3P, $\gamma \delta$, IL-17A, FceR1 $\alpha$, CD117, CD34 (eBioscience Inc.), and F4/80 (Caltag Laoratories, Burlingame, CA).

\section{Flow cytometry}

Standard methodology was employed for the direct immunofluorescence of pulmonary leukocytes. Briefly, in 96well U-bottom plates, $100 \mu$ containing $1 \times 10^{6}$ cells in PBS $+2 \%$ FBS (FACS buffer) were incubated with $50 \mu \mathrm{l}$ of FC $_{\text {Block }}{ }^{\mathrm{TM}}$ (BD Biosciences) diluted in FACS buffer for 5 minutes to block non-specific binding of antibodies to cellular Fc receptors. Subsequently, an optimal concentration of fluorochrome-conjugated antibodies (between 0.06-0.5 $\mu \mathrm{g} / 1 \times 10^{6}$ cells in $50 \mu \mathrm{l}$ of FACS buffer) were added in various combinations to allow for dual or triple staining experiments, and plates were incubated for 30 minutes at $4^{\circ} \mathrm{C}$. Following incubation, the cells were washed three times with FACS buffer and cells were fixed in $200 \mu \mathrm{l}$ of $2 \%$ ultrapure formaldehyde (Polysciences, Inc., Warrington, PA) diluted in FACS buffer (fixation buffer). For intracellular staining, cells remained in fixation buffer for $10 \mathrm{~min}$ at room temperature. After fixation, the cells were washed and permeabilized with $0.1 \%$ saponin for $10 \mathrm{~min}$ at room temperature. While permeabilized, the cells were intracellularly stained with anti-IL-17A (eBioscience Inc.) and/or anti-Fox3P (regulatory $\mathrm{T}$ cell) (eBioscience Inc.) for $30 \mathrm{~min}$ at $4^{\circ} \mathrm{C}$. Cells were then washed 3 times with $0.1 \%$ saponin and then resuspended in fixation buffer before flow cytometry was performed. Cells incubated with either FACS buffer alone or single fluorochrome-conjugated antibodies were used to determine positive staining and spillover/compensation calculations and the flow cytometer determined background fluorescence. The samples were analyzed using BD FACSArray software ${ }^{\mathrm{TM}}$ on a BD FACSArray flow cytometer (BD Biosciences). Dead cells were excluded on the basis of forward angle and $90^{\circ}$ light scatter. For data analyses, 30,000 events (cells) were evaluated from a predominantly leukocytic population identified by backgating from $\mathrm{CD} 45^{+}$-stained cells. The absolute number of total leukocytes was quantified by multiplying the total number of cells observed by hemacytometer counting by the percentage of $\mathrm{CD} 45^{+}$cells determined by flow cytometry. The absolute number of each leukocyte subset (1A8, F4/80, $\mathrm{CD}^{+} 1 \mathrm{c}^{+} / \mathrm{CD} 11 \mathrm{~b}^{\mathrm{int}}$, $\mathrm{CD}_{19}{ }^{+}, \mathrm{CD} 4^{+} / \mathrm{CD}^{+}, \mathrm{CD} 8^{+} / \mathrm{CD}^{+}, \mathrm{CD} 4^{+} / \mathrm{Fox}^{+} \mathrm{p}^{+}$, $\mathrm{CD}^{-} / \mathrm{NK} 46^{+}, \mathrm{CD}^{+} / \mathrm{NKp} 46^{+}, \gamma \delta^{+}$, Siglec-F ${ }^{+} / \mathrm{CD} 11 \mathrm{~b}^{\text {int }}$ was determined by multiplying the percentage of each gated population by the total number of $\mathrm{CD} 45^{+}$cells.

\section{$\gamma \delta^{+} \mathrm{T}$ cell ex vivo IL-17 production}

Following leukocyte enrichment (see above), lung leukocytes from mice treated with either isotype control antibody or with anti-1A8 antibody were enriched for $\gamma \delta^{+} \mathrm{T}$ cells by positive selection using magnetic beads labeled with $\gamma \delta$ antibody according to the manufacturer's recommendations (Miltenyi Biotec, Auburn, CA). Cells were counted, and $1 \times 10^{5}$ cells/well were plated in triplicate in 96-well plates, with either complete media alone or with $100 \mu \mathrm{g} / \mathrm{ml} \mathrm{C}$. neoformans cell wall extract (CWE) [13]. CWE was tested for endotoxin contamination before use, and levels were confirmed to be $<1 \mathrm{EU} / \mu \mathrm{g}$ protein (data not shown). Cells were incubated at $37^{\circ} \mathrm{C}, 5 \% \mathrm{CO}_{2}$ for $24 \mathrm{hr}$. Following incubation, cells were centrifuged and supernatants were removed for quantification of IL-17A by ELISA. Remaining cells were harvested and used for intracellular IL-17A staining by flow cytometry.

\section{Cytokine analysis}

Cytokine levels in lung tissues were analyzed using the Bio-Plex Protein Array System (Luminex-based technology) (Bio-Rad Laboratories, Hercules, CA). Briefly, lung 
tissue was excised and homogenized in ice-cold sterile PBS $(1 \mathrm{ml})$. An aliquot $(50 \mu \mathrm{l})$ was taken to quantify the pulmonary fungal burden and an anti-protease buffer solution $(1 \mathrm{ml})$ containing PBS, protease inhibitors (inhibiting cysteine, serine, and other metalloproteinases) and $0.05 \%$ Triton X-100 was added to the homogenate. Samples were then clarified by centrifugation $(800 \times \mathrm{g})$ for 5 minutes. Supernatants from pulmonary homogenates were assayed using the Bio-Plex Protein Array System (Bio-Rad Laboratories) for the presence of IL-6, IL-10, IL-17A, and granulocyte-colony stimulating factor (G-CSF) expression, as well as the chemokine keratinocyte-derived chemokine (KC) (CXCL1). ELISA assays were performed according to manufacturer's instructions to measure TGF- $\beta$, IL-23 (R\&D Systems), and IL-21 (BD Biosciences) on pulmonary homogenates, and IL-17A ELISA (R\&D Systems) was used to measure IL-17A in cell culture supernatants.

\section{Statistical analysis}

The unpaired Student's $t$ test (two-tailed) was used to analyze fungal burden, pulmonary cell populations, and cytokine/chemokine data using GraphPad Prism version 5.00 for Windows (GraphPad Prism Software, San Diego California USA). For multiple comparisons, a one-way ANOVA with the Tukey's multiple comparison test was performed. Significant differences were defined as $P<0.05$.

\section{Abbreviations}

YPD: Yeast-extract-peptone-dextrose media.

\section{Competing interests}

The authors declare that they have no competing interests.

\section{Authors' contributions}

KW and FW conceived and designed the experiments, KW carried out the experiments, JK contributed knock-out mice, KW, JK, and FW analyzed the data, and KW and FW wrote the manuscript. All authors read and approved the final manuscript.

\section{Acknowledgements}

This work was supported by grant RO1 Al071752-04 from the National Institute of Allergy and Infectious Diseases (NIAID) of the National Institutes of Health (NIH) (F.L.W.).

The content of this report is solely our responsibility and does not necessarily represent the official views of NIAID of the NIH.

\section{Funding}

Supported by research grant RO1 Al071752 from the National Institute of Allergy and Infectious Diseases (NIAID) of the National Institutes of Health $(\mathrm{NIH})$ (F.L.W. Jr.).

\section{Author details}

'Department Biology, The University of Texas at San Antonio, San Antonio, TX 78249-0062, USA. ${ }^{2}$ The South Texas Center for Emerging Infectious Diseases, The University of Texas at San Antonio, San Antonio, TX, USA. ${ }^{3}$ Department of Pediatrics, Children's Hospital of Pittsburgh of UPMC, Pittsburgh, PA, USA.

Received: 27 July 2012 Accepted: 30 November 2012

Published: 7 December 2012

\section{References}

1. Levitz SM: The ecology of cryptococcus neoformans and the epidemiology of cryptococcosis. Rev Infect Dis 1991, 13:1163-1169.

2. Mitchell TG, Perfect JR: Cryptococcosis in the era of AIDS-100 years after the discovery of Cryptococcus neoformans. Clin Microbiol Rev 1995, 8:515-548.

3. Shoham S, Levitz SM: The immune response to fungal infections. Br J Haematol 2005, 129:569-582.

4. Singh N, Gayowski T, Wagener MM, Marino IR: Clinical spectrum of invasive cryptococcosis in liver transplant recipients receiving tacrolimus. Clin Transplant 1997, 11:66-70.

5. Singh N, Dromer F, Perfect JR, Lortholary O: Cryptococcosis in solid organ transplant recipients: current state of the science. Clin Infect Dis 2008, 47:1321-1327.

6. Hill JO, Harmsen AG: Intrapulmonary growth and dissemination of an avirulent strain of cryptococcus neoformans in mice depleted of $\mathrm{CD}^{+}{ }^{+}$or CD8 ${ }^{+}$T-cells. J Exp Med 1991, 173:755-758.

7. Huffnagle GB, Lipscomb MF, Lovchik JA, Hoag KA, Street NE: The role of CD4+ and CD8+ T cells in the protective inflammatory response to a pulmonary cryptococcal infection. J Leukoc Biol 1994, 55:35-42.

8. Huffnagle GB, Yates JL, Lipscomb MF: Immunity to a pulmonary cryptococcus neoformans infection requires both $\mathrm{CD}^{+}$and $\mathrm{CD} 8^{+} \mathrm{T}$-cells. J Exp Med 1991, 173:793-800.

9. Mody CH, Lipscomb MF, Street NE, Toews GB: Depletion of CD4+ (L3T4+) lymphocytes in vivo impairs murine host defense to cryptococcus neoformans. J Immunol 1990, 144:1472-1477.

10. Buchanan $\mathrm{KL}$, Doyle HA: Requirement for $\mathrm{CD}^{+} \mathrm{T}$ lymphocytes in host resistance against cryptococcus neoformans in the central nervous system of immunized mice. Infect Immun 2000, 68:456-462.

11. Wormley FL Jr, Perfect JR, Steele C, Cox GM: Protection against cryptococcosis using a murine interferon-gamma producing cryptococcus neoformans strain. Infect Immun 2007, 75:1453-1462.

12. Wozniak KL, Ravi S, Macias S, Young ML, Olszewski MA, Steele C, Wormley FL: Insights into the mechanisms of protective immunity against cryptococcus neoformans infection using a mouse model of pulmonary cryptococcosis. PLoS One 2009, 4:e6854.

13. Young M, Macias S, Thomas D, Wormley FL Jr: A proteomic-based approach for the identification of immunodominant cryptococcus neoformans proteins. Proteomics 2009, 9:2578-2588.

14. Conti HR, Shen F, Nayyar N, Stocum E, Sun JN, Lindemann MJ, Ho AW, Hai $J H, Y u J J$, Jung JW, et al: Th17 cells and IL-17 receptor signaling are essential for mucosal host defense against oral candidiasis. J Exp Med 2009, 206:299-311.

15. Huang W, Na L, Fidel PL, Schwarzenberger P: Requirement of interleukin17A for systemic anti-candida albicans host defense in mice. J Infect Dis 2004, 190:624-631.

16. Rudner XL, Happel KI, Young EA, Shellito JE: Interleukin-23 (IL-23)-IL-17 cytokine axis in murine pneumocystis carinii infection. Infect Immun 2007, 75:3055-3061.

17. Wuthrich M, Gern B, Hung CY, Ersland K, Rocco N, Pick-Jacobs J, Galles K, Filutowicz $\mathrm{H}$, Warner $T$, Evans $\mathrm{M}$, et al: Vaccine-induced protection against 3 systemic mycoses endemic to north america requires Th17 cells in mice. J Clin Invest 2011, 121:554-568.

18. Loures FV, Pina A, Felonato M, Calich VL: TLR2 is a negative regulator of Th17 cells and tissue pathology in a pulmonary model of fungal infection. J Immunol 2009, 183:1279-1290.

19. Voelz K, Lammas DA, May RC: Cytokine signaling regulates the outcome of intracellular macrophage parasitism by cryptococcus neoformans. Infect Immun 2009, 77:3450-3457.

20. Muller U, Stenzel W, Kohler G, Werner C, Polte T, Hansen G, Schutze N, Straubinger RK, Blessing M, McKenzie ANJ, et al: IL-13 induces diseasepromoting type 2 cytokines, alternatively activated macrophages and allergic inflammation during pulmonary infection of mice with cryptococcus neoformans. J Immunol 2007, 179:5367-5377.

21. Hardison SE, Wozniak KL, Kolls JK, Wormley FL Jr: Interleukin-17 is Not required for classical macrophage activation in a pulmonary mouse model of cryptococcus neoformans infection. Infect Immun 2010, 78:5341-5351.

22. Zhang Y, Wang F, Tompkins KC, McNamara A, Jain AV, Moore BB, Toews GB, Huffnagle GB, Olszewski MA: Robust Th1 and Th17 immunity supports pulmonary clearance but cannot prevent systemic dissemination of 
highly virulent cryptococcus neoformans H99. Am J Pathol 2009, 175:2489-2500.

23. Wozniak KL, Hardison SE, Kolls JK, Wormley FL: Role of IL-17A on resolution of pulmonary C. Neoformans infection. PLoS One 2011, 6:e17204

24. Ferretti S, Bonneau O, Dubois GR, Jones CE, Trifilieff A: IL-17, produced by lymphocytes and neutrophils, is necessary for lipopolysaccharideinduced airway neutrophilia: IL-15 as a possible trigger. J Immuno/ 2003 170:2106-2112.

25. Werner JL, Gessner MA, Lilly LM, Nelson MP, Metz AE, Horn D, Dunaway CW, Deshane J, Chaplin DD, Weaver CT, et al: Neutrophils produce IL-17A in a Dectin-1 and IL-23 dependent manner during invasive fungal infection. Infect Immun 2011, IAl:05493-05411.

26. Andreasen C, Powell DA, Carbonetti NH: Pertussis toxin stimulates IL-17 production in response to bordetella pertussis infection in mice. PLOS One 2009, 4:e7079.

27. Mills $\mathrm{KH}$ : Induction, function and regulation of IL-17-producing T cells. Eur J Immunol 2008, 38:2636-2649.

28. Peck A, Mellins ED: Precarious balance: Th17 cells in host defense. Infect Immun 2010, 78:32-38.

29. Korn T, Bettelli E, Oukka M, Kuchroo VK: IL-17 and Th17 Cells. Annu Rev Immunol 2009, 27:485-517.

30. Ley K, Smith E, Stark MA: IL-17A-producing neutrophil-regulatory Tn lymphocytes. Immunol Res 2006, 34:229-242.

31. Smith E, Stark MA, Zarbock A, Burcin TL, Bruce AC, Vaswani D, Foley P, Ley K: IL-17A inhibits the expansion of IL-17A-producing T cells in mice through "short-loop" inhibition via IL-17 receptor. J Immunol 2008 181:1357-1364.

32. Song C, Luo L, Lei Z, Li B, Liang Z, Liu G, Li D, Zhang G, Huang B, Feng ZH: IL-17-producing alveolar macrophages mediate allergic lung inflammation related to asthma. J Immunol 2008, 181:6117-6124.

33. Kish DD, Li X, Fairchild RL: CD8 T cells producing IL-17 and IFN-gamma initiate the innate immune response required for responses to antigen skin challenge. J Immunol 2009, 182:5949-5959.

34. Nembrini C, Marsland BJ, Kopf M: IL-17-producing T cells in lung immunity and inflammation. J Allergy Clin Immunol 2009, 123:986-994. quiz 995-986.

35. Braun RK, Ferrick C, Neubauer P, Sjoding M, Sterner-Kock A, Kock M, Putney L, Ferrick DA, Hyde DM, Love RB: IL-17 producing gammadelta T cells are required for a controlled inflammatory response after bleomycininduced lung injury. Inflammation 2008, 31:167-179.

36. Romani L, Zelante T, De Luca A, Fallarino F, Puccetti P: IL-17 and therapeutic kynurenines in pathogenic inflammation to fungi. $J$ Immunol 2008, 180:5157-5162.

37. Mednick AJ, Feldmesser M, Rivera J, Casadevall A: Neutropenia alters lung cytokine production in mice and reduces their susceptibility to pulmonary cryptococcosis. Eur J Immunol 2003, 33:1744-1753.

38. Dejima T, Shibata K, Yamada H, Hara H, Iwakura Y, Naito S, Yoshikai Y: Protective role of naturally occurring interleukin-17A-producing gd $\mathrm{T}$ cells in the lung at the early stage of systemic candidiasis in mice. Infect Immun 2011, 79:4503-4510.

39. Zhang X, Majlessi L, Deriaud E, Leclerc C, Lo-Man R: Coactivation of Syk kinase and MyD88 adaptor protein pathways by bacteria promotes regulatory properties of neutrophils. Immunity 2009, 31:761-771.

40. Chaturvedi V, Wong B, Newman SL: Oxidative killing of cryptococcus neoformans by human neutrophils - evidence that fungal mannitol protects by scavenging reactive oxygen intermediates. J Immunol 1996, 156:3836-3840.

41. Dong ZM, Murphy JW: Mobility of human neutrophils in response to cryptococcus neoformans cells, culture filtrate antigen, and individual components of the antigen. Infect Immun 1993, 61:5067-5077.

42. Dong ZM, Murphy JW: Cryptococcal polysaccharides bind to CD18 on human neutrophils. Infect Immun 1997, 65:557-563.

43. Mambula SS, Simons ER, Hastey R, Selsted ME, Levitz SM: Human neutrophil-mediated nonoxidative antifungal activity against cryptococcus neoformans. Infect Immun 2000, 68:6257-6264.

44. Holtmeier W, Kabelitz D: Gammadelta T cells link innate and adaptive immune responses. Chem Immunol Allergy 2005, 86:151-183.

45. Born WK, Reardon CL, O'Brien RL: The function of gd T cells in innate immunity. Curr Opin Immunol 2006, 18:31-38.

46. Wozniak KL, Young ML, Wormley FL Jr: Protective immunity against experimental pulmonary cryptococcosis in T cell-depleted mice. Clin Vacc Immunol 2011, 18:717-723.
47. Gillard GO, Bivas-Benita M, Hovav A-H, Grandpre LE, Panas MW, Seaman MS, Haynes BF, Letvin NL: Thy $1^{+}$NK cells from vaccinia virus-primed mice confer protection against vaccinia virus challenge in the absence of adaptive lymphocytes. PLoS Path 2011, 7:e1002141.

48. Sada-Ovalle I, Chiba A, Gonzales A, Brenner MB, Behar SM: Innate invariant NKT cells recognize mycobacterium tuberculosis infected macrophages, produce interferon-g, and kill intracellular bacteria. PLOS Path 2008, 4:e1000239.

49. Coquet JM, Chakravarti S, Kyparissoudis K, McNab FW, Pitt LA, McKenzie BS, Berzins SP, Smyth MJ, Godfrey DI: Diverse cytokine production by NKT cell subsets and identification of an IL-17-producing CD4-NK1.1- NKT cell population. Proc Natl Acad Sci U S A 2008, 105:11287-11292.

50. Spits H, Di Santo JP: The expanding family of innate lymphoid cells: regulators and effectors of immunity and tissue remodeling. Nat Immunol 2011, 12:21-27.

51. Nishimura H, Yajima T, Kagimoto Y, Ohata M, Watase T, Kishihara K, Goshima F, Nishiyama Y, Yoshikai Y: Intraepithelial gd T cells May bridge a Gap between innate immunity and acquired immunity to herpes simplex virus type 2. J Virol 2004, 78:4927-4930

52. Takatori H, Kanno Y, Watford WT, Tato CM, Weiss G, Ivanov II, Littman DR O'Shea JJ: Lymphoid tissue inducer-like cells are an innate source of IL-17 and IL-22. J Exp Med 2009, 206:35-41.

53. Cua DJ, Tato CM: Innate IL-17-producing cells: the sentinels of the immune system. Nat Rev Immunol, 10:479-489.

54. Milpied P, Massot B, Renand A, Diem S, Herbelin A, Leite-de-Moraes M, Rubio MT, Hermine O: IL-17-producing invariant NKT cells in lymphoid organs are recent thymic emigrants identified by neuropilin-1 expression. Blood, 118:2993-3002.

55. Retini C, Vecchiarelli A, Monari C, Tascini C, Bistoni F, Kozel TR: Capsular polysaccharide of cryptococcus neoformans induces proinflammatory cytokine release by human neutrophils. Infect Immun 1996, 64:2897-2903.

doi:10.1186/1471-2172-13-65

Cite this article as: Wozniak et al:: Depletion of neutrophils in a protective model of pulmonary cryptococcosis results in increased IL17A production by gamma/delta T cells. BMC Immunology 2012 13:65.

\section{Submit your next manuscript to BioMed Central and take full advantage of:}

- Convenient online submission

- Thorough peer review

- No space constraints or color figure charges

- Immediate publication on acceptance

- Inclusion in PubMed, CAS, Scopus and Google Scholar

- Research which is freely available for redistribution 